\title{
SISTEM APLIKASI PENDAFTARAN SKRIPSI BERBASIS MOBILE DI UNIVERSITAS YUDHARTA PASURUAN MENGGUNAKAN METODOLOGI UNIFIED PROCESS
}

\author{
Mukhamad Murtadho, Cahya Bagus Sanjaya \\ Universitas Yudharta Pasuruan \\ Jl. Yudharta No.07 Pandean Sengonagung Purwosari Pasuruan \\ e-mail: murtadho100@gmail.com, cahya.bagus@yudharta.ac.id
}

\begin{abstract}
Abstrak
Universitas Yudharta Pasuruan merupakan Universitas swasta yang berlokasi di Kecamatan Puwosari Kabupaten Pasuruan. Sebagian pelaksanaan pengarsipan Skripsi di Universitas Yudharta Pasuruan masih manual, meskipun telah memiliki aplikasi Sistem Informasi Akademik (SIAKAD) namun belum mencakup pendaftaran skripsi. Permasalahan sekarang adalah sebanyak 95\% mahasiswa Universitas Yudharta Pasuruan yang sedang mengikuti mata kuliah Skripsi yang membutuhkan aplikasi Pendaftaran Skripsi untuk membantu dalam kelancaran pelaksanaan mata kuliah Skripsi. Tujuan dari penelitian ini yaitu untuk pembuatan aplikasi pendaftaran Skripsi berbasis Mobile untuk membantu mahasiswa serta dosen yang dapat diterapkan dalam proses matakuliah Skripsi di Universitas Yudharta Pasuruan. Metode penelitian yang diterapkan pada penelitian ini adalah metodologi Unified Process dari tahap Inception sampai tahap Transisi, dengan menggunakan pemodelan Unified Modeling Language untuk merancang desain aplikasi, serta menggunakan metodelogi Black Box Testing untuk pengujian aplikasi. Aplikasi pendaftaran Skripsi ini diterapkan menggunakan bahasa pemrograman Java, dan Extensible Markup Language. Aplikasi pendaftaran Skripsi ini dapat membantu permasalahan yang ada dengan mencetak pada analisis dan perancangan yang dilakukan, sehingga aplikasi pendaftaran Skripsi ini dapat digunakan pada proses pengerjaan Skripsi di Universitas Yudharta Pasuruan untuk membantu mahasiswa serta dosen dalam kelangsungan pelaksanaan matakuliah Skripsi.
\end{abstract}

Kata Kunci: Aplikasi Pendaftaran Skripsi, Unified Modeling Language, Unified Process.

\section{Pendahuluan}

Seiring dengan berkembangnya Teknologi Informasi serta Komunikasi yang begitu pesat, perkembangan dari sisi hardware ataupun software pun juga akan ikut berkembang dengan pesat. Berbagai lembaga berlomba-lomba untuk melakukan investasi baik dalam infrastruktur, hardware maupun sistem informasi dengan tujuan agar tetap mengikuti perkembangan teknologi dengan tujuan untuk mendukung kegiatan operasional dari lembaga tersebut (Setemen, 2009).

Universitas Yudharta Pasuruan, merupakan salah satu lembaga pendidikan tinggi yang mengembangkan ilmu teknologi dan pengetahuan, mempunyai tanggung jawab yang besar untuk ikut serta dalam mewujudkan dan mensukseskan pembangunan nasional, khusunya pembangunan bidang teknologi.

Dalam rangka mewujudkan cita-cita sebuah perguruan tinggi yang berorientasi pada penciptaan sarjana yang intelektual, profesional, berakhlak mulia serta mampu berbicara secara teoritis dan maupun dalam bentuk prakteknya, maka dari salah satu tujuan perguruan tinggi adalah untuk menghasilkan lulusan-lulusan yang tidak hanya memahami ilmu pengetahuan dan teknologi saja, akan tetapi juga mampu mempraktekkan serta mengembangkan keilmuannya baik di dunia pendidikan maupun di dunia industri.

Lingkup Universitas Yudharta Pasuruan, sudah terdapat sistem informasi berbasis web yang telah diterapkan, yaitu Sistem Informasi Akademik (SIAKAD). SIAKAD merupakan sistem di tingkat universitas yang hanya berfungsi untuk pengisian FRS, dosen memasukkan nilai mata kuliah saja, mahasiswa melihat nilai hasil ujian matakuliah, cetak kartu ujian dan kartu FRS, Melihat Transkip Nilai dan lain-lain, tetapi belum mencakup pada pengelolaan pengajuan Skripsi, Seminar serta Sidang. 
Beberapa aktivitas akademik di Universitas Yudharta masih dilakukan pendokumentasian secara manual seperti: pengurusan Skripsi. Adapun permasalahan dalam penelitian sebelumnya adalah karena adanya berbagai masalah yang timbul seperti kurang terkontrol siapa saja yang sudah diterima dan belum, kurang efisien sistem saat ini. Hal tersebut juga terjadi di Universitas Yudharta Pasuruan. Oleh karena itu, diperlukan sebuah sistem untuk memperbaiki masalah yang ada tersebut.

Berdasarkan uraian di atas, maka diperlukan sebuah "SISTEM APLIKASI PENDAFTARAN SKRIPSI BERBASIS MOBILE DI UNIVERSITAS YUDHARTA PASURUAN MENGGUNAKAN METODOLOGI UNIFIED PROCESS". Aplikasi ini diharapkan menjadi contoh bagi Universitas yang lain dalam bidang teknologi informasi dan pentingnya Aplikasi untuk mempermudah kinerja dalam pengajuan skripsi.

\section{Metode penelitian}

Metodologi yang digunakan pada penelitian ini yaitu metodologi Unified Process yang mana metodologi penelitian ini memiliki 5 (lima) tahapan, diantaranya 1) Tahap Inception/Pengenalan, 2) Tahap Elaborasi, 3) Tahap Konstruksi, 4) Tahap Transisi, dan 5) Tahap Produksi. Namun pada penelitian ini kami hanya membatasi sampai tahap Transisi.

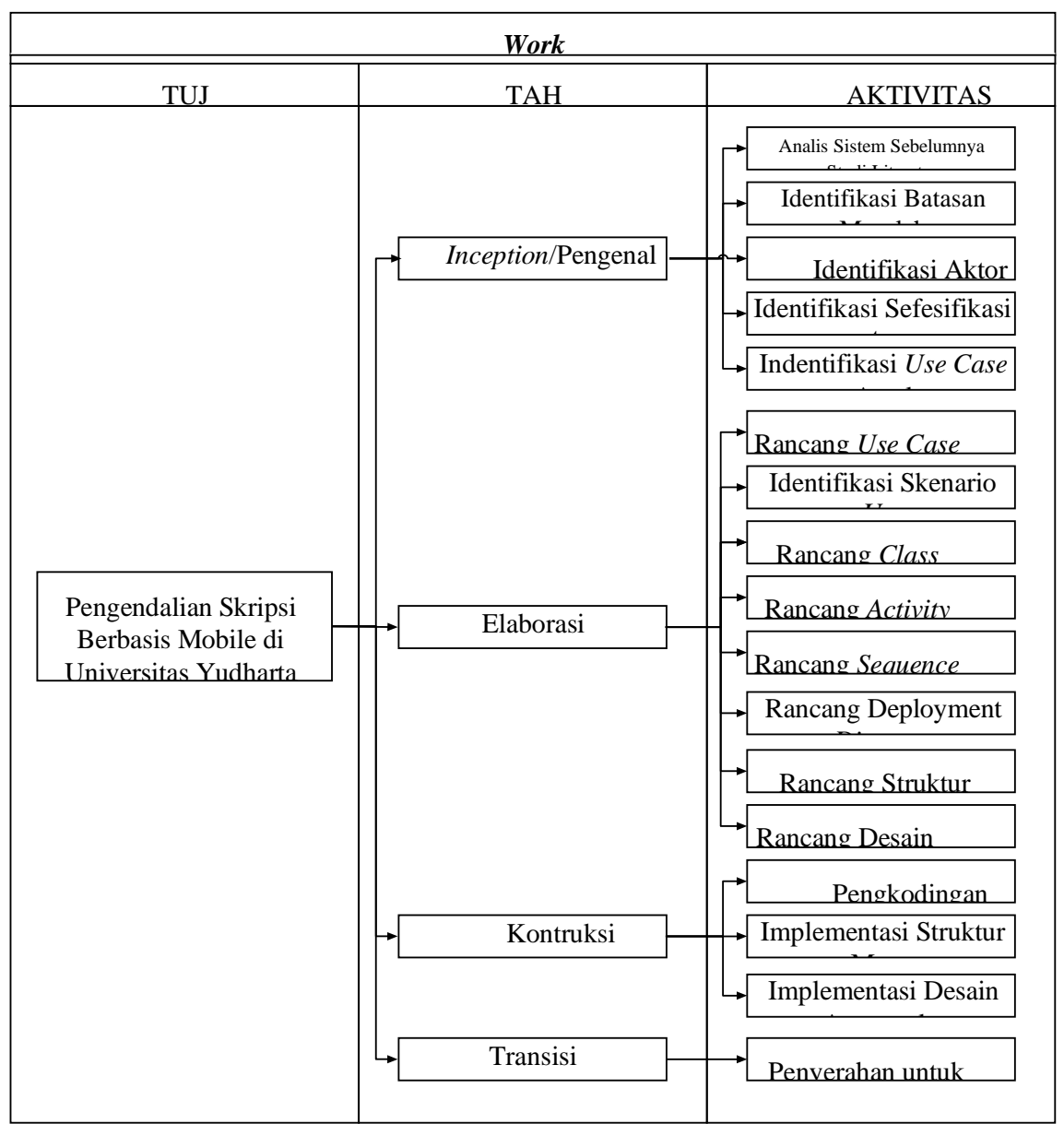

Gambar 1. Work Breakdown Structure

\section{Hasil dan Pembahasan}

\subsection{Identifikasi Aktor}

Identifikasi aktor dilakukan dengan menentukan siapa yang akan menggunakan aplikasi. Adapun aktor yang teridentifikasi untuk aplikasi yang akan dibangun adalah mahasiswa dan dosen. 
Tabel 1. Identifikasi Aktor

\begin{tabular}{|c|c|c|c|c|}
\hline No. & $\begin{array}{l}\text { Nama } \\
\text { Aktor }\end{array}$ & $\begin{array}{l}\text { Klasifikasi } \\
\text { Aktor }\end{array}$ & & $\begin{array}{l}\text { Aktivitas } \\
\text { Aktor }\end{array}$ \\
\hline 1. & Mahasiswa & $\begin{array}{c}\text { Primary } \\
\text { Business Actor }\end{array}$ & $\begin{array}{l}1 . \\
2 . \\
3 . \\
4 . \\
5 . \\
6 . \\
7 . \\
8 . \\
9 . \\
10 . \\
11 .\end{array}$ & $\begin{array}{l}\text { Daftar Akun } \\
\text { Login } \\
\text { Pilih Menu Mahasiswa } \\
\text { Lihat Informasi Skripsi } \\
\text { Kelola Progress Report } \\
\text { Kelola Data Akun (Mahasiwa) } \\
\text { Lihat Data Dosen Pembimbing } \\
\text { Lihat Panduan Skripsi } \\
\text { Unduh Formulir } \\
\text { Ubah Password } \\
\text { Unggah Dokumen Skripsi }\end{array}$ \\
\hline 2. & Dosen & $\begin{array}{l}\text { Primary } \\
\text { Business } \\
\text { Actor }\end{array}$ & $\begin{array}{l}1 . \\
2 . \\
3 . \\
4 . \\
5 . \\
6 . \\
7 . \\
8 .\end{array}$ & $\begin{array}{l}\text { Login } \\
\text { Piih Menu Dosen } \\
\text { Lihat Informasi Skripsi } \\
\text { Kelola Data Akun (Dosen) } \\
\text { Lihat Progress Report MahasiswaBimbingan } \\
\text { Lihat Data Mahasiswa Bimbingan } \\
\text { Lihat Panduan Skripsi } \\
\text { Ubah Password }\end{array}$ \\
\hline
\end{tabular}

\subsection{Implementasi}

Implementasi dari perancangan sistem yang telah dibuat. Pembahasan mencakup implementasi dari aplikasi yang sudah di buat.

\subsubsection{Implementasi Program}

Sebelum mengimplementasi sebuah program penulis mengusulkan beberapa tahapan yang harus dilakukan agar supaya program ini berjalan dengan yang diharapkan.

\subsubsection{Implementasi Antar Muka}

1. Implementasi Halam Login

Halaman ini berisi jika mahasiswa/dosen yang sudah mendaftar yang ingin mengendalikan skripsi.

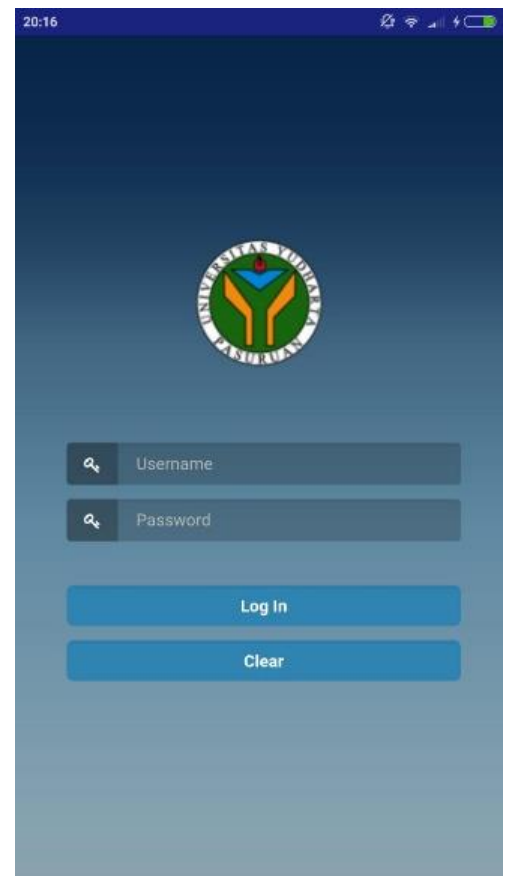

Gambar 2. Halaman Login 
2. Implementasi Halaman Pengendalian

Halaman ini terdapat beberapa aktifitas diantaranya:

1. Pendaftaran Proposal

2. Pendaftaran Seminar hasil

3. Ujian meja

4. Surat ljin Penelitian

5. Berita Acara Proposal

6. Berita Acara Seminar Hasil

7. Berita Acara ujian Meja

8. Daftar Yudisium

9. Pengisian Formulir Pendaftaran Skripsi

10.Cetak SK pembimbing

11.Logout
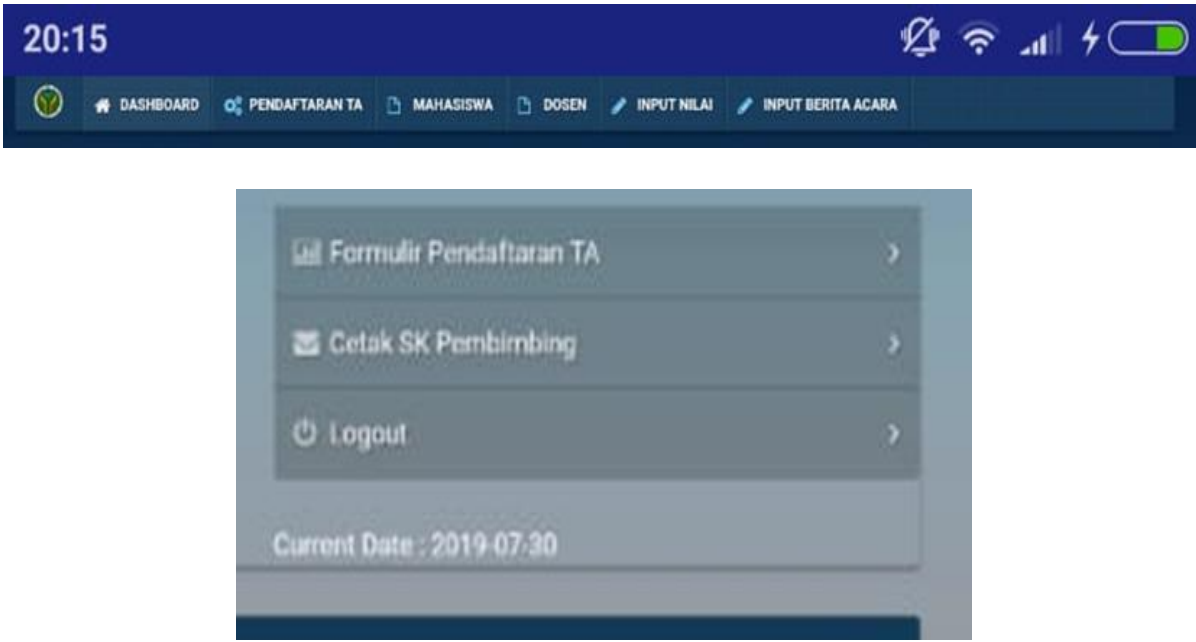

Gambar 3. Halaman Aktifitas Aplikasi

\section{Conclusion}

Dalam Implementasinya aplikasi ini hanya ada satu akun saja yaitu mahasiswa, untuk menyempurnakan aplikasi tersebut perlu adanya akun untuk dosen dan Kaprodi.

\section{Pengakuan dan Penghargaan}

Selama pengerjaan Skripsi ini penulis telah banyak mendapat bimbingan, masukan, motivasi dan arahan dari berbagai pihak. Oleh karena itu, penulis menyampaikan ucapan terima kasih dan penghargaan setinggi-tingginya kepada:

1. KH.Sholeh Bahrudin, selaku Pembina Yayasan Darut Taqwa yang selalu memberikan doa restunnya.

2. Bapak Dr. M. Saifullah, selaku Rektor Universitas Yudharta Pasuruan yang telah mengarahkan dan memberikan motivasi kepada penulis.

3. Bapak Misbach Munir, ST., MT., selaku dekan Fakultas Teknik Universitas Yudharta Pasuruan.

4. Wike Adhi Anggono, ST, Selaku Tata Usaha Fakultas Teknik Universitas Yudharta Pasuruan.

5. Bapak Imron Rosyadi, M.Kom., selaku Ketua Program Studi Informatika.

6. Bapak Cahya Bagus Sanjaya, S.Kom, M.Kom. selaku dosen Pembimbing yang telah memberikan banyak arahan kepada penulis.

7. Kedua orang tua saya yang dengan restunya, do'anya, harapan-harapan serta pengorbanannya menjadikan saya untuk tidak menyerah dalam penyelesaian Skripsi ini.

8. Teman-teman mahasiswa informatika ankatan 2015 yang telah mendukung serta memberikan support kepada penulis.

9. Semua pihak yang terlibat baik secara langsung maupun tidak langsung pada proses penulisan Skripsi ini. 


\section{References}

[1] Latifah, N. (2016). Analisa Dan Perancangan Sistem Penjadwalan Skripsi Berbasis Web Responsif. Universitas Muria Kudus.

[2] Muhammad Zaky Faried, A. M. (2017). Pengembangan Aplikasi Android Bimbingan Skripsi Dengan Fitur Notifikasi . Universitas Negeri Semarang.

[3] P, M. J. (2014). Aplikasi Bimbingan Skripsi Online Mahasiswa Jurusan Pendidikan Matematika Fakultas Matematika Dan Ilmu Pengetahuan Alam Universitas Negeri Yogyakarta. Universitas Negeri Yogyakarta.

[4] Rike Mahara, B. A. (2018). Perancangan Interface Aplikasi E-Skripsi Berbasis Android. Universitas Islam Negeri Ar-Raniry.

[5] Yana Nuryana, A. M. (2017). Pengembangan Aplikasi Pengendalian Skripsi Berbasis Android Untuk Mahasiswa Dan Dosen. Sekolah Tinggi Teknologi Garut.

[6] D. Kurniadi And A. Mulyani, "Implementasi Pengembangan Student Information Terminal (Sit) Untuk Pelayanan Akademik Mahasiswa," Jurnal Algoritma, 2016.

[7] Y. Nurfadilah And R. Setiawan, "Pengembangan Aplikasi Controlling Tugas Akhir Berbasis Web Sisi Mahasiswa, Dosen Dan Staff Usi," Jurnal Algoritma, 2016.

[8] L. H. A. Aslina And R. Setiawan, "Pengembangan Aplikasi Controlling Tugas Akhir Berbasis Web Sisi Koordinator Dan Pemangku Keputusanpengembangan Aplikasi Controlling Tugas Akhir Berbasis Web Sisi Koordinator Dan Pemangku Keputusan," Jurnal Algoritma, 2016.

[9] R. S. Pressman, Rekayasa Perangkat Lunak, Yogyakarta: Andi, 2010. 